\title{
Estabilidade lipídica do pernil e da linguiça frescal de suínos tratados com dietas com alta concentração de ácido fítico
}

\section{Lipid stability of ham and fresh sausages of pigs treated with diets containing high levels of phytic acid}

\author{
Mara Cristina Ribeiro da Costa $^{1}$; Caio Abércio da Silva ${ }^{2 *}$; Ana Maria Bridi ${ }^{3}$; Nilva \\ Aparecida Nicolao Fonseca ${ }^{3}$; Alexandre Oba ${ }^{4}$; Roberta Abrami Monteiro Silva ${ }^{5}$; \\ Piero Agostini da Silva ${ }^{6}$; Mauro Sérgio Ywazaki ${ }^{6}$, Danyel Bueno Dalto ${ }^{7}$
}

\section{Resumo}

O experimento avaliou o efeito de diferentes períodos de inclusão do farelo de gérmen de milho desengordurado (FGMD), como principal ingrediente e fonte de ácido fítico em rações de suínos em fase de terminação, sobre as características químicas, sensoriais e de preservação da oxidação no pernil e na linguiça frescal. Foram utilizados 24 suínos machos de mesma genética comercial com peso médio inicial de 75,408 $\pm 4,407 \mathrm{~kg}$ e idade média de 123 dias. Os tratamentos corresponderam à inclusão de $50 \%$ de FGMD na ração nos períodos de $0,7,14$ e 21 dias antes ao abate. Os animais foram submetidos à alimentação à vontade durante 28 dias pré abate. Após o abate dos animais, o pernil de cada meia carcaça foi coletado e os cortes musculares da peça foram utilizados para a elaboração da linguiça frescal. Nos produtos foram avaliadas a composição química aproximada, a cor e a estabilidade lipídica. O delineamento experimental foi em blocos ao acaso (baseado no peso inicial dos suínos) com seis repetições por tratamento. Não houve efeito de regressão nas características avaliadas, indicando que a inclusão do FGMD não afetou a composição química aproximada e a cor nas amostras. Não foi verificado efeito na estabilidade lipídica de acordo com os períodos de inclusão do FGMD (ácido fítico) na análise de oxidação lipídica. A alta inclusão do FGMD em rações de animais em terminação por até 21 dias antes do abate não favoreceu as características qualitativas e de oxidação dos músculos do pernil e da linguiça frescal.

Palavras-chave: Antioxidante, carne suína, fitato, oxidação lipídica

\begin{abstract}
The experiment evaluated the effects of different periods of inclusion of defatted corn germ meal (DCGM), as a principal ingredient and source of phytic acid in the rations of finishing swine, on the chemical and sensorial characteristics and on the preservation of lipid oxidation of ham and the fresh
\end{abstract}

\footnotetext{
1 Médica Veterinária, Doutora pelo Programa de Pós-Graduação em Ciência Animal/CCA, Universidade Estadual de Londrina, UEL, Londrina, PR. E-mail: dada_costa@hotmail.com

2 Prof. Dr. do Dept ${ }^{\circ}$ de Zootecnia/CCA/Universidade Estadual de Londrina, UEL. Campus Universitário, C P1 6001, CEP 86081990, Londrina, PR. E-mail: casilva@uel.br

3 Prof $^{\mathrm{a}} \mathrm{s} \mathrm{Dr}^{\mathrm{a}} \mathrm{s}$ do Dept ${ }^{\mathrm{o}}$ de Zootecnia/CCA/UEL, Londrina, PR. E-mail: ambridi@uel.br; nilva@uel.br

4 Prof. Dr. do Dept ${ }^{\circ}$ de Zootecnia/CCA/UEL, Londrina, PR. E-mail: oba@uel.br

5 Aluna de Doutorado do Programa de Pós-Graduação em Ciência Animal/CCA/UEL, Londrina, PR. E-mail: ro_abrami@hotmail. com

6 Mestres pelo Programa de Pós-Graduação em Ciência Animal/CCA/UEL, Londrina, PR. E-mail: pieroagostini@hotmail.com; mauro_ywazaki@hotmail.com

7 Aluno de Mestrado do Programa de Pós-Graduação em Ciência Animal/CCA/UEL, Londrina, PR. E-mail: danyelbd@hotmail. com

* Autor para correspondência
} 
sausage. Twenty four borrows with $75.408 \pm 4.407 \mathrm{~kg}$ of initial weight and 123 days of age, with the same genetic basis were used. The experimental treatments were represented by the inclusion of $50 \%$ of DCGM in the finishing swine rations during 0,7,14 and 21 days before of slaughter, where were defined four treatments. The pigs were fed ad libitum during 28 days. After the slaughter, it was collected the ham of the half carcass and samples of the ham's muscles were used to elaborate the fresh sausages. The approximate chemical composition, the color and the lipid stability of ham and fresh sausage were evaluated. The experimental design was a randomized blocks (based on initial pigs weight) with 6 replications per treatment. There were no regression effects over the evaluated parameters, where the DCGM did not affect the approximate chemical composition and the color of the samples. There were no differences between the treatments for ham and fresh sausage for the lipid stability according the different periods of inclusion of DCGM. The high inclusion of DCGM in the finishing pig rations until 21 days before the slaughter didn't improve the quality characteristics and the oxidation of ham and fresh sausage.

Key words: Antioxidant, lipid oxidation, phytate, pork

\section{Introdução}

A linguiça frescal representa o principal produto industrializado derivado da carne suína consumido no Brasil, embora ainda seja incipiente seu padrão de identidade no país (OLIVEIRA; ARAÚJO; BORGO, 2005). O produto deve apresentar no máximo $70 \%$ de umidade, até $30 \%$ de gordura e no mínimo $12 \%$ de proteína (BRASIL, 2000).

Um dos aspectos mais importantes relacionados com a linguiça frescal está associada à sua elaboração. Quando a carne é moída e conseqüente exposta ao ar, esta torna-se muito vulnerável a desenvolver uma maior oxidação lipídica (MORRISSEY et al., 1998), que compromete sua qualidade nutricional e sensorial, gerando componentes tóxicos que podem oferecer riscos à saúde do consumidor (LEE; HENDRICKS, 1995; GHIRETTI et al., 1997).

Neste sentido, a utilização de compostos antioxidantes poderia reduzir estes efeitos deletérios, sendo os antioxidantes naturais atualmente mais valorizados para este fim (COSTA, 2005).

O ácido fítico ou inositol hexafosfato, presente em diversos cereais, representa um potente agente antioxidante natural (GRAF; EATON, 1990; EMPSON; LABUZA; GRAF, 1991; LEE; HENDRICKS, 1995). Sua ação está relacionada à quelação do ferro, um mineral catalisador da oxidação lipídica, presente em alta concentração na carne suína. Segundo Ghiretti et al. (1997), no salame Milano e na mortadela o ácido fítico exógeno (adicionado no produto durante sua elaboração) pode ser uma alternativa ao uso do ascorbato sódico para a preservação das características de cor e estabilidade lipídica.

Veiculado principalmente através dos grãos, o ácido fítico endógeno (administrado para o animal através da ração) demonstrou também efeitos positivos na prevenção da oxidação lipídica da carne de suínos alimentados com rações à base de milho, farelo de soja e alta inclusão de farelo de gérmen de milho desengordurado (FGMD), um co-produto da indústria de extração do óleo do milho que contém elevados níveis de ácido fítico (HARBACH et al., 2007).

Todavia, o aproveitamento do ácido fítico dietético pelos monogástricos ainda gera polêmica, não obstante Seynaeve et al. (1999) terem indicado que os animais de estômago simples apresentam satisfatória absorção do ácido fítico, que se acumula principalmente no tecido muscular (SAKAMOTO; VUCENIK; SHAMSUDDIN, 1993).

Neste sentido, o objetivo deste estudo foi avaliar o fornecimento de rações com $50 \%$ de inclusão do FGMD, como principal ingrediente veiculador do ácido fítico na dieta, nos períodos de 0 a 21 dia pré abate, sobre a oxidação do pernil e da linguiça frescal. 


\section{Material e Métodos}

As carnes utilizadas neste estudo foram provenientes de 24 suínos machos castrados de linhagem comercial Agroceres-PIC, adquiridos no início da fase de terminação com peso médio de $75,408 \pm 4,407 \mathrm{~kg}$. Os animais foram alojados em baias individuais, onde receberam água e ração à vontade durante o período experimental de 28 dias.

Os tratamentos experimentais corresponderam aos períodos de inclusão de $50 \%$ de FGMD na ração antes do abate, sendo: T0 - ração controle (isento de FGMD) fornecida durante quatro semanas; T7 - ração com 50\% de FGMD fornecida durante sete dias antes do abate; T14 - ração com 50\% de FGMD durante 14 dias antes do abate e; T21 - ração com 50\% de FGMD fornecida durante 21 dias antes do abate. As rações controle e com $50 \%$ de inclusão de FGMD foram isoenergéticas e isoprotéicas e formuladas visando atender as exigências mínimas dos suínos na fase de terminação, segundo o NRC (1998). A composição e os valores nutricionais das rações estão demonstrados na Tabela 1. Os níveis de ácido fítico foram quantificados no milho, no farelo de soja e no FGMD, segundo metodologia descrita por Latta e Eskin (1980) e modificada por Ellis e Morris (1986).

Tabela 1. Composição percentual e calculada das rações experimentais controle (sem farelo de gérmen de milho desengordurado) e teste (com farelo de gérmen de milho desengordurado).

\begin{tabular}{|c|c|c|}
\hline Ingredientes & Ração controle & Ração teste \\
\hline Milho & 72,187 & 33,546 \\
\hline Farelo de soja & 14,991 & 10,832 \\
\hline Farelo de gérmen de milho desengordurado & 0,000 & 50,000 \\
\hline Inerte & 7,102 & 0,000 \\
\hline Óleo de soja & 2,500 & 2,647 \\
\hline Fosfato bicálcico & 1,846 & 1,081 \\
\hline Calcário & 0,674 & 1,167 \\
\hline Suplemento vitamínico ${ }^{1}$ & 0,400 & 0,400 \\
\hline Sal & 0,250 & 0,250 \\
\hline Suplemento mineral ${ }^{2}$ & 0,050 & 0,050 \\
\hline$\underline{\text { Lisina }}$ & 0,000 & 0,027 \\
\hline \multicolumn{3}{|l|}{ Valores calculados $^{3}$} \\
\hline Cálcio (\%) & 0,800 & 0,800 \\
\hline Energia digestível $(\mathrm{kcal} / \mathrm{kg})$ & 3250 & 3250 \\
\hline Fibra bruta $(\%)$ & 4,662 & 3,193 \\
\hline Fósforo total (\%) & 0,600 & 0,600 \\
\hline Fósforo digestível (\%) & 0,390 & 0,390 \\
\hline Gordura (\%) & 5,127 & 5,112 \\
\hline Lisina $(\%)$ & 0,611 & 0,600 \\
\hline Metionina $(\%)$ & 0,220 & 0,235 \\
\hline Proteína bruta $(\%)$ & 13,200 & 13,200 \\
\hline Ácido fítico $(\%)^{4}$ & 0,840 & 2,140 \\
\hline
\end{tabular}

${ }_{1}$ Suplemento vitamínico por kg do produto: vit.A, 550.000 UI; vit.D3 150.000 UI; vit.E, 2.500UI; vit.K3, 550mg; vit. B1, 175mg; vit.B2, 900mg; vit.B12, 3.000mcg; ácido fólico, $150 \mathrm{mg}$; ácido pantotênico, 3.000mg; niacina, 4.750 $\mathrm{mg}$; selênio, $75 \mathrm{mg}$; antioxidante, $2,5 \mathrm{~g}$.

2 Suplemento mineral por kg do produto: Fe, 90.000mg; Cu, 16.000mg; Mg, 30.000mg; Zn, 140.000mg; Co, 200mg; I, $850 \mathrm{mg}$; Se, 120mg.

${ }^{3}$ Calculado com base nas tabelas da EMBRAPA (1991)

${ }^{4}$ Quantificado no milho, no farelo de soja e no farelo de gérmen de milho desengordurado (LATTA; ESKIN, $1980 \mathrm{e}$ modificado por ELLIS; MORRIS, 1986). 
Os suínos foram abatidos com peso vivo médio de $104,554 \pm 4,807 \mathrm{~kg}$ num frigorífico da região, seguindo as normas de abate humanitário, dentro da rotina do estabelecimento. Após o abate, as carcaças foram mantidas em refrigeração $\left(4^{\circ} \mathrm{C}\right)$ e 24 horas depois os pernis do lado direito de cada carcaça foram encaminhados ao laboratório de análises de produtos de origem animal da Universidade Estadual de Londrina. Os pernis foram dissecados e os músculos biceps femoris separados para análise da cor e da oxidação lipídica. O m. semitendinosus foi reservado para o preparo da linguiça frescal, sendo realizadas posteriormente as análises de cor, oxidação lipídica e composição química aproximada do produto processado. Foram preparadas uma linguiça de cada animal, constituindo, portanto, cada unidade uma repetição.

A avaliação da cor e de oxidação lipídica foi realizada na carne refrigerada, mantida a $4^{\circ} \mathrm{C}$ durante 14 dias após o abate, e na carne congelada a $-5^{\circ} \mathrm{C}$ aos 62 dias após o abate, sendo sempre protegidas da luz.

A linguiça frescal foi preparada obedecendo à seguinte formulação: 97,171\% de pernil; $2,010 \%$ de sal refinado; $0,100 \%$ de açúcar cristal; 0,703\% de pimenta do reino moída e $0,015 \%$ de sal de nitrito. Após o preparo da mistura o produto foi embutido em tripas naturais e separado em amostras, sendo estas armazenadas em temperatura de refrigeração $\left(4^{\circ} \mathrm{C}\right)$ e protegidas da luz. Foi realizada a composição química aproximada (matéria seca, matéria mineral e lipídios) e efetuada a avaliação da cor e da oxidação lipídica da linguiça. A avaliação da cor ocorreu logo após o preparo do produto e aos cinco e aos 12 dias após sua confecção e a oxidação lipídica aos 5 e aos 12 dias após a confecção da linguiça. As leituras foram feitas em triplicata e realizadas da porção interna do produto.
A análise de lipídios totais foi realizada através da extração em Soxhlet (INSTITUTO ADOLFO LUTZ, 1985). A avaliação da cor foi desenvolvida através de um colorímetro, baseado no sistema de cor CIELAB: luminosidade ( $\left.\mathrm{L}^{*}\right)$, componente vermelho-verde $\left(\mathrm{a}^{*}\right)$ e componente amarelo-azul $\left(b^{*}\right)$, e com esses valores foi possível calcular o índice de saturação (c*) e o ângulo de tonalidade (h*), conforme citado por Bridi e Silva (2009). Para a análise da oxidação lipídica utilizouse o método indicativo de substâncias reativas ao ácido tiobarbitúrico (TBARS), segundo Tarladgis, Pearson e Dugan Junior (1964), modificado por Torres et al. (1986). Todas as análises foram feitas em triplicata.

O delineamento experimental foi em blocos ao acaso (baseado nos pesos médios dos animais no início do experimento), com quatro tratamentos (período de inclusão do FGMD na ração) e seis repetições por tratamento. Os resultados foram analisados através de análise de regressão.

\section{Resultados e Discussão}

O FGMD utilizado neste experimento continha 3,39\% de ácido fítico na matéria natural, valor semelhante aos encontrados por outros autores (LEAL, 2000; COSTA, 2005) e pode ser considerado a principal fonte de ácido fítico nas dietas experimentais. O consumo total de ácido fítico durante todo o experimento foi de 764,60; 1066,$03 ; 1374,25$ e 1643,01 g, respectivamente, para os tratamentos com $0,7,14$ e 21 dias de inclusão de FGMD nas rações.

Os dados referentes às análises de cor (valores de $\left.\mathrm{L}^{*}, \mathrm{a}^{*}, \mathrm{~b}^{*}, \mathrm{c}^{*} \mathrm{e} \mathrm{h}^{*}\right)$ e oxidação lipídica do pernil dos suínos que receberam os tratamentos experimentais estão demonstrados na Tabela 2 e Figuras 1 e 2, respectivamente. 
Tabela 2. Efeito do período de inclusão de 50\% de farelo de gérmen de milho desengordurado (FGMD) na ração de suínos na fase de terminação sobre luminosidade $\left(\mathrm{L}^{*}\right)$, componente vermelho-verde $\left(\mathrm{a}^{*}\right)$, componente amarelo-azul ( $\left.\mathrm{b}^{*}\right)$, índice de saturação $\left(\mathrm{c}^{*}\right)$ e ângulo de tonalidade $\left(\mathrm{h}^{*}\right)$ do pernil 14 dias após o abate mantido em refrigeração e 62 dias após o abate mantido congelado.

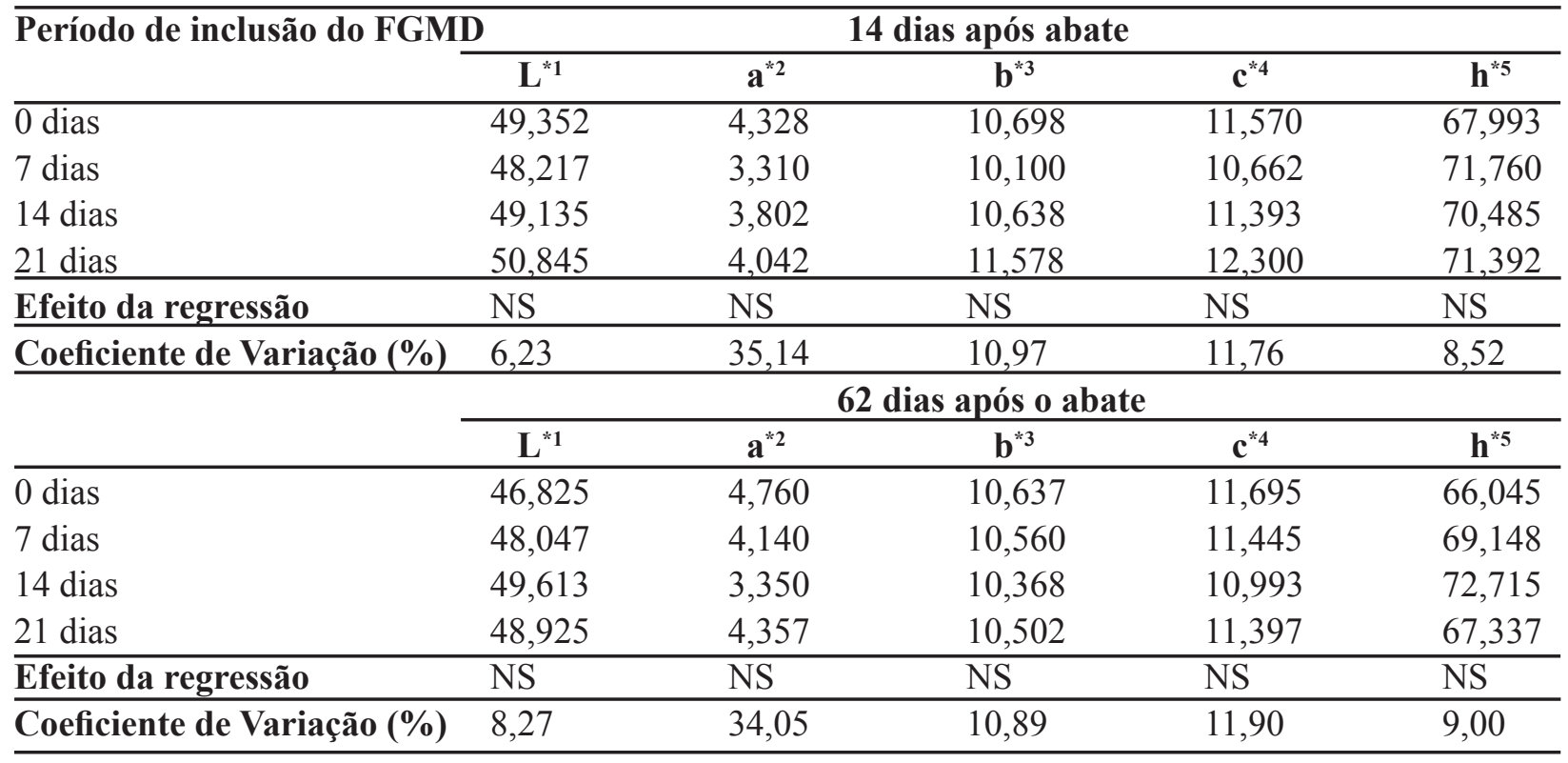

NS - Não significativo $(\mathrm{P}>0,05)$

${ }^{1} 0 \leq \mathrm{L}^{*} \leq 100$ corresponde do preto ao branco, respectivamente;

${ }^{2}-a^{*}$ até $+a^{*}$ corresponde do verde ao vermelho, respectivamente;

${ }^{3}-\mathrm{b}^{*}$ até $+\mathrm{b}^{*}$ corresponde do azul ao amarelo, respectivamente;

${ }^{4} c^{*}=\left(a^{*} 2+b^{*} 2\right)^{0,5}$

${ }^{5} \mathrm{~h} *=\tan -1(\mathrm{~b} * / \mathrm{a} *)$.

Não foi verificado efeito de regressão entre os tratamentos $(\mathrm{P}>0,05)$ para as características avaliadas. A inclusão do FGMD na ração, determinando uma maior concentraçao de ácido fítico na dieta, não foi suficiente para promover efeitos protetivos distintos à oxidaçao da membrana das fibras musculares, resultando na manutençao de um estatus de cor do pernil semelhante entre os tratamentos.

De acordo com os valores obtidos na avaliação de oxidação lipídica, não houve efeito da ação antioxidante do ácido fitico sobre o pernil. Costa (2005) testou a inclusão de até 40\% de FGMD na ração de suínos em terminação durante 28 dias e encontrou uma diminuição na oxidação de $37 \%$ entre o tratamento com $0 \%$ e $40 \%$ de inclusão de FGMD em pernis armazenados sob congelamento. A ausência de efeito no presente trabalho pode ser devido à baixa oxidação durante o período de armazenamento, uma vez que sob baixas temperaturas (refrigeração e congelamento) a intensidade das reações de oxidação diminuem, ou devido ao curto intervalo de inclusão do FGMD (21 dias) antes do abate, sendo este possivelmente insuficiente para permitir alguma ação antioxidante do ácido fítico.

Os dados referentes às análises de composição centesimal e à cor $\left(L^{*}, a^{*}, b^{*}, c^{*} e h^{*}\right)$ verificados nos pernis utilizados na produção da linguiça frescal e na linguiça ao 0,5 e 12 dias após seu preparo estão demonstrados nas Tabelas 3 e 4, respectivamente. Os valores de oxidação lipídica da linguiça nos períodos de 5 e 12 dias após o preparo estão demonstrados na Figuras 3 e 4.

Não foi verificado efeito de regressão $(\mathrm{P}>0,05)$ para as características avaliadas nas amostras de linguiça (Tabela 3). A inclusão do FGMD e, consequentemente, ácido fítico na dieta dos suínos não alterou a composição do produto elaborado a partir da carne destes. 
Figura 1. Valores de TBARS ( $\mathrm{mg} / \mathrm{kg}$ ) do pernil refrigerado durante 12 dias de suínos que receberam rações com $50 \%$ de farelo de gérmen de milho desengordurado (FGMD) na dieta em diferentes períodos antes do abate.

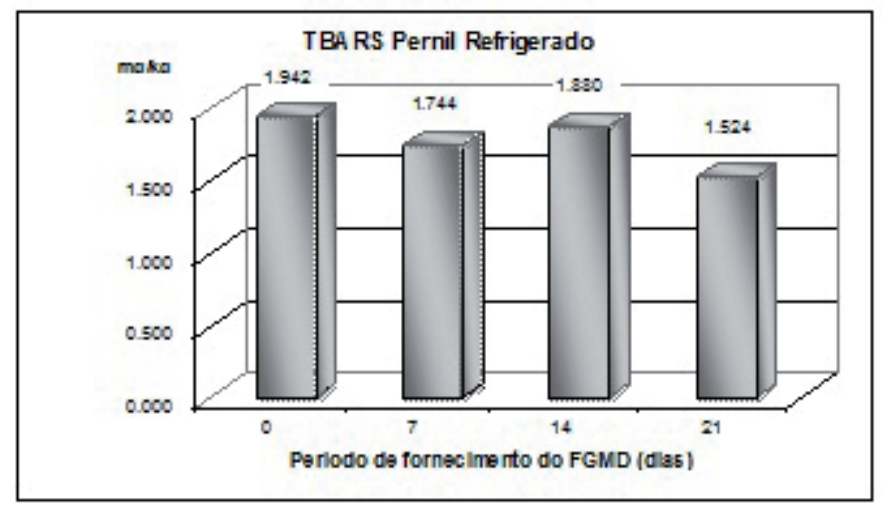

Figura 2. Valores de TBARS $(\mathrm{mg} / \mathrm{kg})$ do pernil congelado durante 50 dias de suínos que receberam rações com $50 \%$ de farelo de gérmen de milho desengordurado (FGMD) na dieta em diferentes períodos antes do abate.

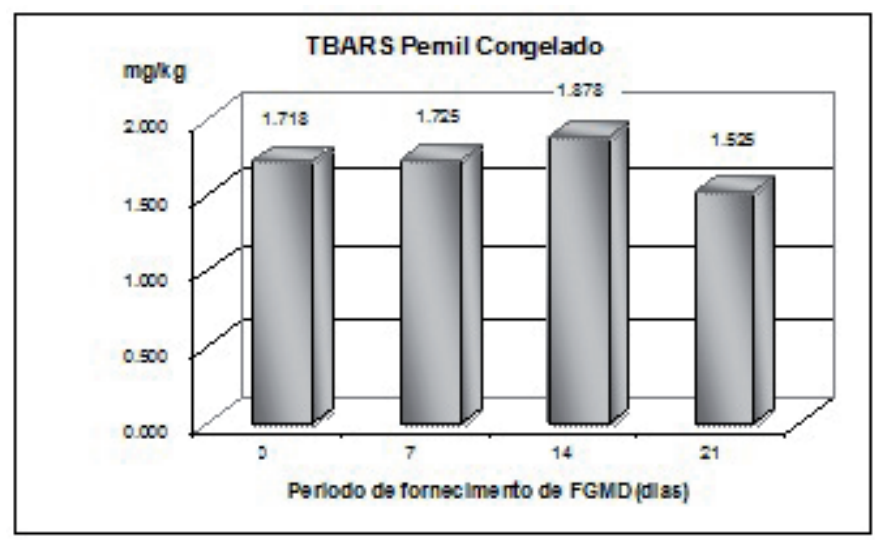

Tabela 3. Efeito do período de inclusão de $50 \%$ de farelo de gérmen de milho desengordurado (FGMD) na ração de suínos na fase de terminação sobre a composição química aproximada da linguiça frescal.

\begin{tabular}{lccc}
\hline Período de inclusão do FGMD & \multicolumn{3}{c}{ Linguiça frescal } \\
\cline { 2 - 4 } & Umidade (\%) & Matéria Mineral (\%) & Extrato Etéreo (\%) \\
\hline 0 dias & 29,382 & 9,613 & 0,330 \\
7 dias & 28,267 & 10,125 & 0,203 \\
14 dias & 28,345 & 9,875 & 0,258 \\
21 dias & 29,170 & 9,798 & 0,360 \\
\hline Efeito da regressão & NS & NS & NS \\
\hline Coeficiente de Variação (\%) & 3,33 & 6,23 & 36,23 \\
\hline
\end{tabular}

NS - Não significativo $(\mathrm{P}>0,05)$. 
Figura 3. Valores de TBARS $(\mathrm{mg} / \mathrm{kg}$ ) da linguiça tipo frescal, armazenada durante 5 dias, proveniente de suínos que receberam $50 \%$ de farelo de gérmen de milho desengordurado (FGMD) na dieta em diferentes períodos antes do abate.

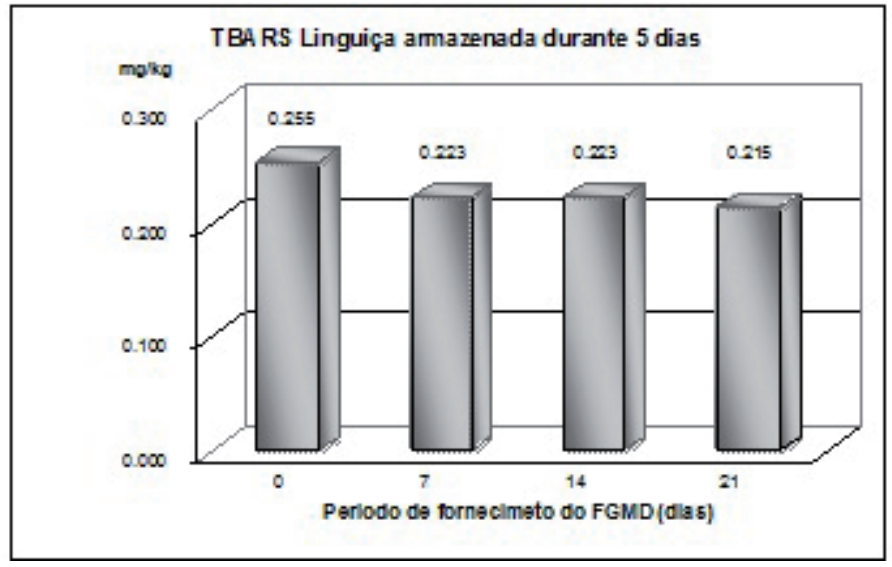

Figura 4. Valores de TBARS (mg/kg) da linguiça tipo frescal, armazenada durante 12 dias, proveniente de suínos que receberam $50 \%$ de farelo de gérmen de milho desengordurado (FGMD) na dieta em diferentes períodos antes do abate.

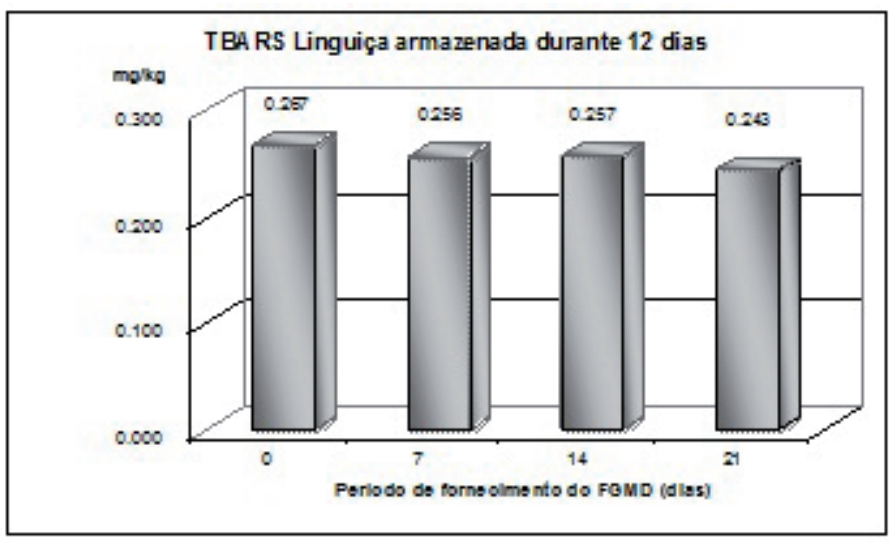

Para os valores de cor e oxidação lipídica (Tabela 4 e Figura 2, respectivamente) foi observado que, independentemente do período de armazenamento da linguiça, os diferentes periodos de inclusão do FGMD não influenciou os resultados. A oxidação lipídica foi considerada baixa, provavelmente pela carne utilizada no preparo ter permanecido congelada e protegida da luz, reduzindo a velocidade das reações de oxidação. Outra hipótese pode decorrer da quantidade de sal de nitrito, conhecido como um importante conservante de produtos cárneos (SHAHIDI, 1992), e do açucar utilizado, considerado um codjuvante tecnológico classificado como estabilizante nestes produtos (LARPENT, 1995). Estes dois produtos podem ter sido suficientes para preservar a oxidação lipídica. 
Tabela 4. Efeito do período de inclusão de $50 \%$ de farelo de gérmen de milho desengordurado (FGMD) na ração de suínos na fase de terminação sobre a luminosidade $\left(\mathrm{L}^{*}\right)$, componente vermelho-verde (a*), componente amarelo-azul ( $\left.b^{*}\right)$, índice de saturação $\left(\mathrm{c}^{*}\right)$ e ângulo de tonalidade $\left(\mathrm{h}^{*}\right)$ do pernil utilizado no preparo da linguiça e na linguiça aos 0,5 e 12 dias após o preparo.

\begin{tabular}{|c|c|c|c|c|c|}
\hline \multicolumn{3}{|l|}{ Período de inclusão do FGMD } & \multicolumn{3}{|l|}{ Pernil } \\
\hline & $\mathbf{L} * 1$ & $a^{* 2}$ & $\mathbf{b}^{* 3}$ & $\mathrm{c}^{* 4}$ & $h^{* 5}$ \\
\hline 0 dias & 60,182 & 9,410 & 14,007 & 16,903 & 56,232 \\
\hline 7 dias & 61,438 & 8,708 & 13,993 & 16,510 & 58,203 \\
\hline 14 dias & 62,757 & 10,285 & 15,050 & 18,273 & 56,193 \\
\hline 21 dias & 61,545 & 9,190 & 14,122 & 16,922 & 57,333 \\
\hline Efeito da regressão & NS & NS & NS & NS & NS \\
\hline \multirow[t]{3}{*}{ Coeficiente de Variação (\%) } & 3,35 & 21,57 & 8,14 & 11,10 & 7,80 \\
\hline & \multicolumn{5}{|c|}{ Linguiça 0 dia após o preparo } \\
\hline & $\mathbf{L}^{* 1}$ & $a^{* 2}$ & $b^{* 3}$ & $c^{* 4}$ & $h^{* 5}$ \\
\hline 0 dias & 52,333 & 4,322 & 14,237 & 14,905 & 73,295 \\
\hline 7 dias & 53,348 & 4,648 & 14,810 & 15,532 & 72,667 \\
\hline 14 dias & 52,548 & 3,895 & 13,288 & 13,877 & 73,822 \\
\hline 21 dias & 53,390 & 4,478 & 14,647 & 15,338 & 73,227 \\
\hline Efeito da regressão & NS & NS & NS & $\mathbf{N S}$ & $\mathbf{N S}$ \\
\hline \multirow[t]{3}{*}{ Coeficiente de Variação (\%) } & 3,35 & 21,57 & 8,14 & 11,10 & 7,80 \\
\hline & \multicolumn{5}{|c|}{ Linguiça 5 dias após o preparo } \\
\hline & $\mathbf{L}^{* 1}$ & $a^{* 2}$ & $\mathbf{b}^{* 3}$ & $\mathrm{c}^{* 4}$ & $h^{* 5}$ \\
\hline$\overline{0 \text { dias }}$ & 50,917 & 8,323 & 14,260 & 16,550 & 60,032 \\
\hline 7 dias & 50,910 & 8,670 & 13,373 & 15,963 & 57,017 \\
\hline 14 dias & 52,148 & 7,363 & 13,230 & 15,157 & 61,000 \\
\hline 21 dias & 51,078 & 8,068 & 12,937 & 15,270 & 58,140 \\
\hline Efeito da regressão & $\mathbf{N S}$ & $\mathbf{N S}$ & $\mathbf{N S}$ & $\mathbf{N S}$ & $\mathbf{N S}$ \\
\hline \multirow[t]{3}{*}{ Coeficiente de Variação (\%) } & 3,75 & 15,38 & 7,11 & 7,60 & 6,19 \\
\hline & \multicolumn{5}{|c|}{ Linguiça 12 dias após o preparo } \\
\hline & $\mathbf{L}^{* 1}$ & $\mathbf{a}^{* 2}$ & $\mathbf{b}^{* 3}$ & $c^{* 4}$ & $h^{* 5}$ \\
\hline 0 dias & 47,282 & 7,498 & 11,868 & 14,057 & 57,642 \\
\hline 7 dias & 47,080 & 7,018 & 10,688 & 12,947 & 57,312 \\
\hline 14 dias & 50,592 & 7,867 & 13,292 & 15,457 & 59,485 \\
\hline 21 dias & 48,378 & 8,120 & 12,477 & 14,953 & 57,928 \\
\hline Efeito da regressão & $\mathbf{N S}$ & $\mathbf{N S}$ & $\mathbf{N S}$ & $\mathbf{N S}$ & $\mathbf{N S}$ \\
\hline Coeficiente de Variação (\%) & 7,69 & 29,51 & 15,60 & 17,54 & 10,61 \\
\hline
\end{tabular}

NS - Não significativo $(\mathrm{P}>0,05)$

${ }^{1} 0 \leq \mathrm{L}^{*} \leq 100$ corresponde do preto ao branco, respectivamente;

${ }^{2}-\mathrm{a}^{*}$ até $+\mathrm{a}^{*}$ corresponde do verde ao vermelho, respectivamente;

${ }^{3}-b^{*}$ até $+b^{*}$ corresponde do azul ao amarelo, respectivamente;

${ }^{4} \mathrm{c}^{*}=(\mathrm{a} * 2+\mathrm{b} * 2) 0,5$

${ }^{5} \mathrm{~h} *=\tan -1(\mathrm{~b} * \mathrm{a} *)$. 
Apesar do ácido fítico ter ser seu efeito antioxidante comprovado no lombo suino in natura (HARBACH et al., 2007) e no pernil congelado (COSTA, 2005), a inclusão de 50\% do FGMD como principal fonte de ácido fítico na ração de suínos em terminação por até 21 dias antes do abate não foi suficiente para determinar efeitos semelhantes na linguiça frescal e no pernil.

\section{Conclusão}

Nas condições estudadas a inclusão de $50 \%$ de FGMD na dieta de suínos nos períodos de 0 a 21 dias pré-abate não alterou a cor e a oxidação lipídica do pernil e da linguiça frescal.

\section{Referências}

BRASIL, Ministério da Agricultura, Pecuária e Abastecimento (MAPA) - Instrução Normativa $n^{\circ} 4$. Anexo III - Regulamento Técnico de Identidade $e$ Qualidade de linguiça. D.O.U., 05 de abril de 2000. Disponível em: <http://www. URl: agricultura.gov.br/ sda/dipoa. $>$. Acesso em: 03 jan. 2009.

BRIDI, A. M.; SILVA, C. A. Avaliação da carne suína. 2. ed. Londrina: Midiograf, 2009.

COSTA, M. C. R. Farelo de gérmen de milho desengordurado na alimentação de suínos como fonte de ácido fítico. 2005. Dissertação (Mestrado em Ciência Animal) - Universidade Estadual de Londrina, Londrina.

ELLIS, R.; MORRIS, R. Appropriate resin selection for rapid phytate analysis by ion-exchange chromatography. Cereal Chemistry, Manhattan, v. 63, n. 1, p. 58-59, 1986.

EMPRESA BRASILEIRA DE PESQUISA AGROPECUÁRIA - EMBRAPA. Tabela de composição química e valores energéticos de alimentos para suínos e aves. 3. ed. Concórdia: Centro Nacional de Pesquisa de Suínos e Aves, 1991.

EMPSON, K. L.; LABUZA, T. P.; GRAF, E. Phytic acid as a food antioxidant. Journal of Food Science, Chicago, v. 56, n. 2, p. 560-563, 1991.

GHIRETTI，G. P.; ZANARDI，E.; NOVELLI，E.; CAMPANINI, G.; DAZZI, G.; MADARENA, G.; CHIZZOLINI, R. Comparative evaluation of some antioxidants in salame milano and mortadella production. Meat Science, Amsterdam, v. 47, n.1/2, p. 167-176, 1997.
GRAF, E.; EATON, J. W. Antioxidant functions of phytic acid. Free Radical Biology \& Medicine, Japan, v. 8, n. 1, p. 61-69, 1990.

HARBACH, A. P. R.; COSTA, M. C. R.; SOARES, A. L.; BRIDI, A. M.; SHIMOKOMAKI, M.; SILVA, C. A.; IDA, E. I. Dietary corn germ containing phytic acid prevents pork meat lipid oxidation while maintaining normal animal growth performance. Food Chemistry, Davis, v. 100, n. 25, p. 1630-1633, 2007.

INSTITUTO ADOLFO LUTZ - IAL. Normas analíticas do Instituto Adolfo Lutz. Métodos físicos e químicos para análise de alimentos. 3. ed. São Paulo: Instituto Adolfo Lutz, 1985.

LARPENT, J. P. Produtos cárnicos fermentados. In: BOURGEOIS, C. M.; LARPENT, J. P. Microbiologia alimentaria. Zaragoza: Ed. Acríbia, 1995. v. 2, p. 271279; 309-320.

LATTA, M.; ESKIN, M. A simple e rapid method for phytate determination. Journal Agriculture Food Chemistry, Davis, v. 28, n. 6, p. 1313-1315, 1980.

LEAL, E. S. Extração, obtenção e caracterização parcial de ácido fitico do germe grosso de milho e aplicação como antioxidante. 2000. Dissertação (Mestrado em Ciência de Alimentos) - Universidade Estadual de Londrina, Londrina.

LEE, B. J.; HENDRICKS, D. G. Phytic acid protective effect against beef round muscle lipid peroxidation. Journal of Food Science, Chicago, v. 60, n. 2, p. 241244, 1995.

MORRISSEY, P. A.; SHEEHY, P. J. A.; GALVIN, K.; KERRY, J. P.; BUCKLEY, D. J. Lipid stability in meat and meat products. Meat Science, Amsterdam, v. 49, n. 1, p. 73-86, 1998.

NATIONAL RESEARCH COUNCIL - NRC. Nutrient requirements of swine. 10. ed. Washington: National Academy Press, 1998. 189 p.

OLIVEIRA, J. M.; ARAÚJO, W. M. C.; BORGO, L. A. Quantificação de nitrato e nitrito em linguiças do tipo frescal. Ciência e Tecnologia de Alimentos, Campinas, v. 25, n. 4, p.736-742, 2005.

SAKAMOTO, K.; VUCENIK, I.; SHAMSUDDIN, A. M. [3H] Phytic acid (inositol hexaphosphate) is absorbed and distributed to various tisues in rats. Nutrient Metabolism, n. 123, p. 713-720, 1993.

SEYNAEVE, M.; JANSSES, G.; HESTA, M.; VAN NEVEL, C.; DE WILDE, R. O. Effects of dietary $\mathrm{Ca} / \mathrm{P}$ ratio, $\mathrm{P}$ level and microbial phytase supplementation on nutrient digestibility in growing pigs: breakdown of phytic acid, partition of $\mathrm{P}$ and phytase activity along the 
intestinal tract. Journal Animal Physiology and Animal Nutrition, Oxford, v. 83, n. 4/5, p. 193-204, 1999.

SHAHIDI, F. Prevention of lipid oxidation in muscle foods by nitrite and nitrite-free composition. ACS Symposium Series, Canadá, v. 500, p. 161-182, 1992.

TARLADGIS, B. G.; PEARSON, A. M.; DUGAN JUNIOR, L. R. Chemistry of the 2-thiobarbituric test for determination of oxaditive rancidity in foods II. Formation of the TBA-malonaldehyde complex without acid-heat treatment. Journal of the Science of Food and Agriculture, Davis, v. 15, n. 9, p. 602-607, 1964.

TORRES, E. A. F. S.; AZEVEDO, C. H. M.; CARVALHO JUNIOR, B. C.; LANDGRAF, M.; FRANCO, B. D. G. M.; SHIMOKOMAKI, M. Charque V- modificações da sua qualidade durante o processamento. In: CONGRESSO DA SOCIEDADE BRASILEIRA DE CIÊNCIA E TECNOLOGIA DE ALIMENTOS, 9., 1986, Curitiba. Resumos... Curitiba: Sociedade Brasileira de Ciência e Tecnologia de Alimentos, 1986. p. 45. 